\title{
Hablamos Juntos (Together We Speak): Interpreters, Provider Communication, and Satisfaction with Care
}

\author{
Gerardo Moreno, MD, MSHS ${ }^{1,2}$ and Leo S. Morales, MD, PhD ${ }^{3,4}$
}

'Robert Wood Johnson Clinical Scholars Program at UCLA, Los Angeles, CA, USA; ${ }^{2}$ Department of Family Medicine, David Geffen School of Medicine at UCLA, Los Angeles, CA, USA; ${ }^{3}$ Group Health Research Institute, Seattle, WA, USA; ${ }^{4}$ Department of Health Services, School of Public Health University of Washington, Seattle, WA, USA.

BACKGROUND: The Hablamos Juntos-Together We Speak (HJ)—national demonstration project targeted the improvement of language access for Spanishspeaking Latinos in areas with rapidly growing Latino populations. The objective of HJ was to improve doctorpatient communication by increasing access to and quality of interpreter services for Spanish-speaking patients.

OBJECTIVE: To investigate how access to interpreters for adult Spanish-speaking Latinos is associated with ratings of doctor/office staff communication and satisfaction with care.

DESIGN: Cross-sectional cohort study.

PATIENTS: A total of 1,590 Spanish-speaking Latino adults from eight sites across the United States who participated in the outpatient HJ evaluation.

MEASUREMENTS: We analyzed two multi-item measures of doctor communication (4 items) and office staff helpfulness (2 items), and one global item of satisfaction with care by interpreter use. We performed regression analyses to control for patient sociodemographic characteristics, survey year, and clustering at the site of care. RESULTS: Ninety-five percent of participants were born outside the US, $81 \%$ were females, and survey response rates ranged from $45 \%$ to $85 \%$ across sites. In this cohort of Spanish-speaking patients, those who needed and always used interpreters reported better experiences with care than their counterparts who needed but had interpreters unavailable. Patients who always used an interpreter had better adjusted ratings of doctor communication [effect size (ES=0.51)], office staff helpfulness $(\mathrm{ES}=0.37)$, and satisfaction with care $(\mathrm{ES}=0.37)$ than patients who needed but did not always use an interpreter. Patients who needed and always used interpreters also reported better experiences with care in all three domains measured [doctor communication $(\mathrm{ES}=$ 0.30 ), office staff helpfulness ( $E S=0.21)$, and satisfaction with care $(\mathrm{ES}=0.23)$ ] than patients who did not need interpreters.

CONCLUSIONS: Among adult Spanish-speaking Latinos, interpreter use is independently associated with higher satisfaction with doctor communication, office staff helpfulness, and ambulatory care. Increased

Received September 17, 2009

Revised February 15, 2010

Accepted July 1, 2010

Published online August 12, 2010 attention to the need for effective interpreter services is warranted in areas with rapidly growing Spanishspeaking populations.

KEY WORDS: doctor-patient communication; Latino population; interpreter services; immigrants; disparities; limited English proficient. $\mathrm{J}$ Gen Intern Med 25(12):1282-8

DOI: $10.1007 /$ s11606-010-1467-x

(c) Society of General Internal Medicine 2010. This article is published with open access at Springerlink.com

\section{INTRODUCTION}

The last 20 years have been marked by unparalleled increases in Latino populations across many communities in the US. Between 2000 and 2006, Latinos accounted for onehalf of the nation's growth and have increased dramatically in many Midwestern and Southern areas of the country. Arkansas and Georgia, for example, experienced a $60 \%$ growth rate in their Latino population during that period ${ }^{1}$. The Latino migration to new areas of the US has made the provision of language access services in those areas a challenge for health care systems $^{2-6}$. Indeed, this demographic shift poses daunting linguistic challenges to health care providers who may be providing medical treatment to significant numbers of linguistically diverse patients for the first time. A recent survey study found that physicians in communities with small but expanding Latino populations report more language barriers than do physicians practicing in major Latino population centers ${ }^{7}$.

Research has documented that Latinos with limited English proficiency (LEP) face barriers to receiving high quality health care services $^{8-10}$. Specifically, Latinos who speak Spanish are less satisfied with provider communication than Englishspeaking patients ${ }^{11-13}$. For Latinos who need interpretive services, studies have documented the important benefits of utilizing professional interpreters ${ }^{14-16}$. In one of the first studies of interpreters, Spanish-speaking patients who received care in the ED and communicated through an interpreter or who did not have an interpreter when they thought one was necessary were less satisfied with the patient-provider relationship compared to their counterparts that did not need interpreters ${ }^{17}$. In a recent hospital study, uninsured Spanishspeaking adults who used interpreters were more satisfied with provider communication than those who did not use interpreters ${ }^{18}$. Less research has focused on the relationships between interpreter use and the combination of patient satisfaction with care, provider communication, and office 
staff helpfulness within a Latino cohort in ambulatory care settings.

Our purpose in conducting this study was to investigate the associations between the use of interpreters and patient ratings of provider communication and satisfaction with care among Spanish-speaking adults receiving ambulatory health care services. We hypothesized that Spanish-speaking Latinos, who need and use interpreters, will report higher ratings of provider-communication and satisfaction with care than those who do not use them. This study expands on previous studies in a number of ways, including (1) using data from adult patients with and without insurance coverage; (2) examining data from a large cohort of adult Spanish-speaking Latinos; and (3) including patients from communities that have recently experienced large increases in Latino populations.

\section{METHODS}

\section{Sample}

We analyzed cross-sectional pooled data from 2003 and 2006 of 1,590 Spanish-speaking Latino adults that participated in the evaluation of the Hablamos Juntos (HJ) national demonstration project $^{19}$. HJ was funded by the Robert Wood Johnson Foundation targeting language access for Latinos with LEP in multiple sites across the US with a primary objective to improve doctorpatient communication by increasing access to and quality of interpreter services for Spanish-speaking patients. The eight clinical sites that participated in the outpatient program evaluation were located in Alabama, Nebraska, Pennsylvania, Rhode Island, South Carolina, Texas, California, and Washington. The $\mathrm{HJ}$ selection criteria required that sites be located in areas that had recently experienced large growths in Latino populations.

Two methods were used to recruit participants in the survey (passive versus active consent). For six sites, administrative record and surname analysis was used to identify and contact potential Latino participants (passive). For the remaining two other sites, patients were recruited directly in clinic waiting rooms (active). The survey response rates ranged from $45 \%$ to $85 \%$ across sites, and the survey was conducted by bilingual interviewers using computer-assisted telephone interviews (CATI). Higher response rates were obtained in sites that used active consent recruitment than those that used passive consent recruitment. The CATI survey took on average $22 \mathrm{~min}$ to complete, and up to 15 callbacks were made at various times of the day and days of the week. No contact information or incorrect contact information accounted for $90 \%$ of the nonresponse. The remaining 10\% were due to ineligibility, not English or Spanish speaking, or refusal to participate. The incentive to complete the survey was $\$ 10$, and patients who initially refused were called back to attempt refusal conversions. The protocol was approved by the RAND Corporation (Santa Monica, CA) IRB and the IRB at each clinical site. A general evaluation of the $\mathrm{HJ}$ national initiative has been published ${ }^{19,20}$.

\section{Dependent Variables}

We examined four survey items that asked patients to rate (in the last 6 months) the quality of doctor communication in four areas: (1) listening carefully to patients; (2) explaining things in a way patients could understand; (3) showing respect for what patients have to say; and (4) spending enough time with patients. Two additional items asked patients about office staff communication in their doctor's office in two areas: (1) being courteous and respectful; and (2) being helpful. The response options to these six questions were administered using a 4-point response scale (never, sometimes, usually, and always) and used to calculate composite sores (0-100 scale) for doctor communication and office staff helpfulness. We also examined a single global item of patient ratings of satisfaction with overall ambulatory health care provided over the last 6 months (0-10 scale). These items were adapted from the Consumer Assessment of Health Plans Survey (CAHPS $®)^{21}$ and culturally tailored if necessary to specific HJ settings and population.

\section{Independent Variables}

Patients were classified into three groups ${ }^{11,17,18,22,23}$ based on how they responded to two questions about interpreters during the last 6 months. Those patients who did not need interpreters were categorized as "interpreter not needed." They represent the gold standard or patients who should ideally experience clinical encounters that facilitate sound conditions for healthful doctor-patient communication. Patients who needed interpreters were asked a follow-up question about how frequently they had interpreters available for use (response options: always, usually, sometimes, and never). All patients were put into one of the following categories: interpreter not needed, interpreter needed and always available, or interpreter needed but not available. Because of sample size considerations, those who answered usually/sometimes/never were put into the final category.

We also examined an additional set of survey items on patient sociodemographic characteristics including age (categorized as 18-29 years, 30-44 years, and $\geq 45$ years), gender (dichotomous), marital status (dichotomous), education (categorized as $>6$ years of school, between 7-12 years of school, and $>12$ years of school). Patients were asked how many people were supported by income that they (and/or their spouse or partner) earn. Based on this household size, interviewers calculated the incomes corresponding to the poverty level and 1/ 2 the poverty level. We used the 2002 (survey wave 1) and 2005 (survey wave 2) US federal poverty guidelines to determine the federal poverty level. Interviewers used a series of questions using the poverty level corresponding to the reported household size to determine whether the respondent's income was above the poverty level, between $1 / 2$ and at the poverty level, or less then $1 / 2$ the poverty level.

Finally, we analyzed items that asked patients about health insurance coverage (insured versus uninsured), self-rated health status (response options: excellent, very good, good, fair, and poor), and presence of selected chronic conditions (diabetes, hypertension, asthma, and high cholesterol). We constructed dichotomous variables to indicate survey year (wave) and recruitment method.

\section{Statistical Analysis}

We used Stata (version 10.1) statistical software to conduct all analyses for this study. The dependent variables for this study 
were composed of two multi-item composite measures of doctor communication (4 items), office staff communication (2 items), and one global item on satisfaction with overall ambulatory care. The composite scores were computed by transforming the item scores linearly to a metric with a possible range of $0-100$ and then averaging across items in the same scale. The internal consistency reliability for the doctor communication composite, assessed with Cronbach's alpha statistic, was 0.82 . Mean scores for satisfaction with care and the office staff communication composite scores $(\alpha=$ 0.74) were calculated in similar fashion.

We computed frequencies to describe the sample's characteristics and need and use of interpreters. One-way analysis of variance (ANOVA) was then used to assess statistically significant unadjusted differences between mean scores for patient ratings of care across items by use and availability of interpreters.

The income item had 19\% missing values and was imputed five times using (Stata version 10.1) multiple imputations by a chained equations (ICE) statistical program, which uses an iterative multivariable regression imputation technique ${ }^{24}$. All other independent variables that we examined had less than $0.6 \%$ missing values. For this study, an a priori decision was made to not profile or rank individual study sites, but rather to focus on patient reports of care with respect to communication and satisfaction with care. We used studies in the literature to guide our selection of covariates and model factors that influence provider communication and patient satisfaction with care $^{12,17,22,23,25}$. Using the imputed dataset, we conducted three multiple variable linear regression models to estimate the impact of interpreters on our three outcome measures while adjusting for survey year and clustering ${ }^{26}$ at the site of care [intraclass correlation coefficient $(\mathrm{ICC})=0.020-0.026$ ]. Finally, we estimated the adjusted composite and global rating scores.

We replicated our regression models discounting participants with missing data and found little difference in results from those obtained with imputed data. In other analyses, we also controlled for the number of physician visits and number of selfreported chronic conditions (diabetes, hypertension, high cholesterol, and asthma), but found no difference in the results from those reported (data not shown). We also conducted a series of sensitivity analyses for all outcome measures by including a variable that indicated the type of recruitment method but, again, found no difference from the reported coefficients and standard errors (data not shown). Finally, because of skewness in the distribution of responses, we transformed each dependent variable by dividing its square root by 100 and re-estimated each model using the transformed dependent variables. However, we only found a small difference in the coefficients and standard errors and report the results using untransformed dependent variables. For all analyses in this study, a p-value of $<0.05$ was used to determine statistical significance.

\section{RESULTS}

\section{Sample Characteristics}

The mean age of $\mathrm{HJ}$ participants was 39 years $(\mathrm{SD}=13)$, and $81 \%$ of them were female (Table 1). Approximately $69 \%$ of
Table 1. Sociodemographic Characteristics, Health Status, and Insurance Coverage Among Hablamos Juntos Survey Participants $(\mathrm{N}=1,590)$

\begin{tabular}{|c|c|c|}
\hline Characteristic & Freq $(n=1,590)$ & $\%$ \\
\hline \multicolumn{3}{|l|}{ Age (years) } \\
\hline $18-29$ & 423 & 27 \\
\hline $30-44$ & 666 & 42 \\
\hline$\geq 45$ & 501 & 31 \\
\hline Female & 1,293 & 81 \\
\hline \multicolumn{3}{|l|}{ Education (years) } \\
\hline $0-6$ & 597 & 38 \\
\hline $7-11$ & 495 & 31 \\
\hline$\geq 12$ & 476 & 30 \\
\hline \multicolumn{3}{|l|}{ Marital status } \\
\hline Married & 848 & 54 \\
\hline Separated, divorced, widowed & 370 & 24 \\
\hline Never married, single & 355 & 22 \\
\hline Insured & 1,108 & 70 \\
\hline \multicolumn{3}{|l|}{ Family income* } \\
\hline Less than $1 / 2$ the poverty level & 323 & 25 \\
\hline $1 / 2$ to at the poverty level & 494 & 38 \\
\hline Above the poverty level & 475 & 37 \\
\hline Labor force participation $\dagger$ & 996 & 63 \\
\hline \multicolumn{3}{|l|}{ Birthplace } \\
\hline United States & 76 & 5 \\
\hline Mexico & 843 & 53 \\
\hline Central America & 216 & 14 \\
\hline Caribbean & 344 & 22 \\
\hline South America/Other & 102 & 6 \\
\hline \multicolumn{3}{|l|}{ Self-reported health status } \\
\hline Excellent & 109 & 7 \\
\hline Very good & 161 & 10 \\
\hline Good & 491 & 31 \\
\hline Fair & 684 & 43 \\
\hline Poor & 134 & 9 \\
\hline \multicolumn{3}{|c|}{ Household size (adults and children) } \\
\hline $1-2$ & 220 & 14 \\
\hline $3-4$ & 684 & 44 \\
\hline $5-6$ & 512 & 33 \\
\hline $7+$ & 148 & 9 \\
\hline
\end{tabular}

* Poverty level was calculated using the US federal poverty guidelines. Two items were used to determine poverty level including (1) the number of people supported by income that respondent and/or their spouse or partner earn, and (2) total household income amount. †Employed or looking for employment

participants had completed less than 12 years of school, and about half (54\%) of them were married. Having any type of health insurance was reported by $70 \%$ of participants, and $63 \%$ had at least one chronic condition (diabetes, asthma, hypertension, high cholesterol, or depression). Sixty-three percent of participants reported US citizenship. Fifty-three percent of participants were of Mexican ethnic origin, with the second largest group being from the Caribbean $(22 \%$; includes Puerto Ricans). Fair or poor health status was self-reported by $52 \%$ of participants.

Ninety-nine percent of patients responded to the survey in Spanish. Eighteen percent of respondents indicated that they did not need an interpreter, and of those who needed an interpreter, 39\% indicated that one was always made available. Thirteen percent of respondents indicated they needed an interpreter and never had one available. The rest of participants indicated that they needed an interpreter and usually or sometimes had one available. The need and use of interpreters ranged from $71-92 \%$ and $57-83 \%$ between sites, respectively. 
Table 2. Unadjusted Doctor Communication, Office Staff Helpfulness, and Satisfaction with Care Scores and Standard Errors (SE) by Interpreter Need and Use

\begin{tabular}{|c|c|c|c|c|}
\hline & \multirow{2}{*}{$\begin{array}{l}\begin{array}{l}\text { Did not } \\
\text { need } \\
\text { interpreter }\end{array} \\
\text { score (SE) }\end{array}$} & \multicolumn{2}{|c|}{ Need interpreter } & \multirow[t]{2}{*}{$P$-value } \\
\hline & & $\begin{array}{l}\text { always } \\
\text { available } \\
\text { score (SE) }\end{array}$ & $\begin{array}{l}\text { Not } \\
\text { available } \\
\text { score (SE) }\end{array}$ & \\
\hline \multicolumn{5}{|c|}{ Doctor communication } \\
\hline $\begin{array}{l}\text { Doctor listens } \\
\text { carefully }\end{array}$ & $\begin{array}{l}88.33 \\
(1.43)\end{array}$ & $\begin{array}{l}93.11 \\
(0.78)\end{array}$ & $\begin{array}{l}83.21 \\
(1.02)\end{array}$ & $<0.001$ \\
\hline $\begin{array}{l}\text { Doctor explains } \\
\text { things well }\end{array}$ & $\begin{array}{l}87.07 \\
(1.51)\end{array}$ & $\begin{array}{l}90.95 \\
(0.89)\end{array}$ & $\begin{array}{l}80.01 \\
(1.15)\end{array}$ & $<0.001$ \\
\hline $\begin{array}{l}\text { Doctor respects } \\
\text { your comments }\end{array}$ & $\begin{array}{l}89.88 \\
(1.39)\end{array}$ & $\begin{array}{l}93.81 \\
(0.77)\end{array}$ & $\begin{array}{l}85.14 \\
(1.03)\end{array}$ & $<0.001$ \\
\hline $\begin{array}{l}\text { Doctor spends } \\
\text { enough time }\end{array}$ & $\begin{array}{l}86.26 \\
(1.55)\end{array}$ & $\begin{array}{l}91.98 \\
(0.83)\end{array}$ & $\begin{array}{l}80.33 \\
(1.09)\end{array}$ & $<0.001$ \\
\hline \multicolumn{5}{|l|}{ Doctor's staff } \\
\hline $\begin{array}{l}\text { Staff courteous } \\
\text { and respectful }\end{array}$ & $\begin{array}{l}84.75 \\
(1.54)\end{array}$ & $\begin{array}{l}89.77 \\
(0.95)\end{array}$ & $\begin{array}{l}81.11 \\
(1.11)\end{array}$ & $<0.001$ \\
\hline Staff helpful & $\begin{array}{l}80.78 \\
(1.67)\end{array}$ & $\begin{array}{l}87.13 \\
(1.01)\end{array}$ & $\begin{array}{l}76.68 \\
(1.16)\end{array}$ & $<0.001$ \\
\hline \multicolumn{5}{|l|}{ Global rating } \\
\hline $\begin{array}{l}\text { Satisfaction with } \\
\text { health care }\end{array}$ & $\begin{array}{l}88.85 \\
(0.96)\end{array}$ & $\begin{array}{l}92.30 \\
(0.58)\end{array}$ & $\begin{array}{l}85.99 \\
(0.67)\end{array}$ & $<0.001$ \\
\hline
\end{tabular}

Note: The responses to individual items were transformed into $0-100$ scale with 100 representing the best score

*Statistically significant at a p-value $<0.001$ level as assessed by oneway ANOVA

\section{Unadjusted Scores}

Table 2 shows individual item scores for composite and global measures by interpreter need and use among HJ participants. Among the four items that compose the doctor communication composite score, patients rated doctor communication the lowest when asked about time and explanations. The item that queried patients about staff helpfulness had the lowest mean scores regardless of need and use of interpreter services. Individual mean scores were greatest for the global item on satisfaction with overall health care. All seven individual items varied significantly ( $\mathrm{p}$-value $<0.001$ ) across interpreter need and use categories.

\section{Multivariate Results}

Table 3 reports multivariate regression results for the patient communication composite and satisfaction measures. Always using an interpreter was strongly and independently associated with greater satisfaction with overall care and doctor/staff communication. Specifically, always using an interpreter was independently associated with a 6.04 [standard error $(\mathrm{SE})=1.47$; $p$-value <0.001] and a $5.29(\mathrm{SE}=1.83$; $\mathrm{p}$-value $<0.001)$ point increase in doctor and staff communication scores, respectively, compared to scores from patients who indicated that they did not need an interpreter. Always using an interpreter was independently associated with a $3.65(\mathrm{SE}=1.19$; $\mathrm{p}$-value $<0.01)$ point

Table 3. Multivariate Regression Results for Doctor and Office Staff Communication Composite Scores and Satisfaction with Health Care Global Scores for Hablamos Juntos Participants

\begin{tabular}{|c|c|c|c|c|c|c|}
\hline & \multicolumn{2}{|c|}{ Doctor communication } & \multicolumn{2}{|c|}{$\begin{array}{l}\text { Office staff } \\
\text { communication }\end{array}$} & \multicolumn{2}{|c|}{$\begin{array}{l}\text { Satisfaction with health } \\
\text { care }\end{array}$} \\
\hline Patient characteristics and interpreter need and use & \multicolumn{2}{|c|}{$\beta$-Coefficient (SE) } & \multicolumn{2}{|c|}{$\beta$-Coefficient (SE) } & \multicolumn{2}{|c|}{$\beta$-Coefficient (SE) } \\
\hline Did not need interpreter & REF & - & REF & - & REF & - \\
\hline Need interpreter, always available & $6.04 \ddagger$ & $(1.47)$ & $5.29 \ddagger$ & $(1.83)$ & $3.65 \dagger$ & (1.19) \\
\hline Need interpreter, not available & $-4.28 \ddagger$ & $(1.42)$ & $-3.78^{*}$ & $(1.77)$ & $-2.39 *$ & $(1.15)$ \\
\hline \multicolumn{7}{|l|}{ Age } \\
\hline $18-29$ years & $\mathrm{REF}$ & - & REF & - & $\mathrm{REF}$ & - \\
\hline 30-44 years & -0.04 & $(1.24)$ & 0.82 & $(1.54)$ & 0.63 & $(1.00)$ \\
\hline$\geq 45$ years & $4.18 \ddagger$ & $(1.38)$ & $6.35 \ddagger$ & $(1.71)$ & $4.72 \ddagger$ & $(1.12)$ \\
\hline Female & -1.89 & $(1.31)$ & -0.12 & $(1.62)$ & $-2.24^{*}$ & (1.06) \\
\hline Married & -1.23 & $(1.04)$ & $-3.25^{*}$ & $(1.27)$ & -0.49 & $(0.82)$ \\
\hline \multicolumn{7}{|l|}{ Education (years completed) } \\
\hline$\geq 12$ years & REF & - & REF & - & REF & - \\
\hline $7-11$ years & 0.33 & $(1.27)$ & -0.75 & $(1.57)$ & $2.04 *$ & $(1.02)$ \\
\hline $0-6$ years & -0.09 & $(1.28)$ & 2.09 & $(1.59)$ & $2.12^{*}$ & $(1.04)$ \\
\hline \multicolumn{7}{|l|}{ Family income for household size } \\
\hline Above the poverty level & $\mathrm{REF}$ & - & REF & - & REF & - \\
\hline $1 / 2$ to at the poverty level & 0.81 & $(1.46)$ & -2.06 & (1.64) & -0.14 & $(1.04)$ \\
\hline Less than half the poverty level & 1.96 & $(1.37)$ & -2.14 & $(1.84)$ & -0.28 & $(1.11)$ \\
\hline Insured & $2.90^{*}$ & $(1.11)$ & 1.10 & $(1.38)$ & 1.08 & $(0.89)$ \\
\hline \multicolumn{7}{|l|}{ Self-rated health status } \\
\hline Excellent & REF & - & REF & - & REF & - \\
\hline Very good & -1.15 & $(2.45)$ & -5.03 & (3.03) & -2.48 & $(1.97)$ \\
\hline Good & -3.07 & $(2.10)$ & -1.29 & $(2.59)$ & $-5.01 \ddagger$ & $(1.68)$ \\
\hline Fair & $-5.13^{*}$ & $(2.05)$ & $-5.26^{*}$ & $(2.53)$ & $-6.86 \ddagger$ & (1.64) \\
\hline Poor & $-12.78 \ddagger$ & $(2.57)$ & $-8.52^{*}$ & $(3.18)$ & $-12.87 \ddagger$ & $(2.08)$ \\
\hline Predicted mean composite score & 87.18 & $(\mathrm{SD}=5.95)$ & 83.30 & $(\mathrm{SD}=6.00)$ & 88.99 & $(\mathrm{SD}=4.54)$ \\
\hline
\end{tabular}

$* p<0.05 ; \ddagger p<0.01 ; \ddagger p<0.001$

$R E F=$ referent category

$\mathrm{SD}=$ standard deviation

Notes: (1) Model adjusted for survey wave (year) and site of care using random-effects models. A comparison with fixed effects found little difference in results, and both fixed effects and random effects models yielded consistent results under the Hausman-Wu test. We only report results from more efficient random effects models. (2) Poverty level was calculated using the US federal poverty guidelines (2002 and 2005). 
increase in overall satisfaction with ambulatory care. Needing and not having an interpreter available for use was significantly associated with a $-4.28(\mathrm{SE}=1.42 ; \mathrm{p}$-value $<0.001)$ point decrease in doctor communication score compared to patients who did not need interpreters.

Being of older age ( $\geq 45$ years) was associated with a greater satisfaction with care on all satisfaction measures. Having insurance was significantly associated with a $2.90(\mathrm{SE}=1.11$; p-value $<0.05$ ) point increase in doctor communication scores. Self-reporting poor or fair health status was independently associated with lower ratings of care for all three outcome measures compared to those reporting excellent health.

\section{Adjusted Scores}

Figure 1 shows adjusted mean communication and satisfaction with care scores by need and use of interpreters.
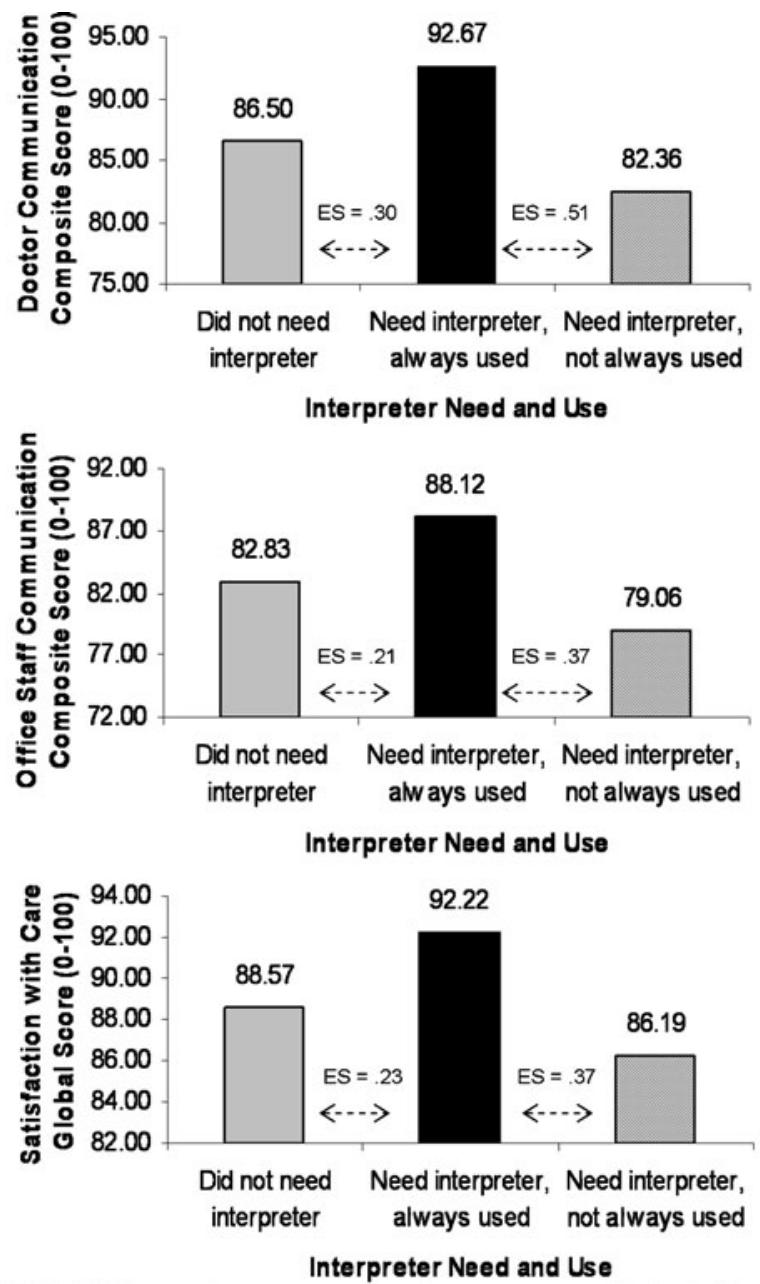

NOTES: 1) Differences in means across respective scores were statistically significant at a $p$ value of $<0.001$ as assessed using one-way ANOVA for test of null hypothesis that all mean scores, in respective categories, are equal. Higher scores (range 0-100) indicate greater patient satisfaction with doctor/office staff communication and satisfaction with care; 2) ES= effect size of difference in means between categories for each outcome; and 3) scores ad effect size of difference in means between categories for each outcome; and 3) scores adjusted for age, gender, marital status, education, income, insurance coverage, self-rated health status, survey wave (year), and clustering at the site of care (using random eftect

Figure 1. Adjusted doctor communication, office staff communication, and satisfaction with care scores by interpreter need and use among Hablamos Juntos (Together We Speak) participants.
Communication and satisfaction with care scores were highest among patients who needed and always had an interpreter available. Use of an interpreter had its largest positive effect on doctor communication scores and its smallest effect on patient satisfaction with care.

\section{DISCUSSION}

In this study of Spanish-speaking Latinos, we find that use of interpreters is independently associated with increased satisfaction with health care and doctor and office staff communication. Specifically, the communication and satisfaction scores were highest for patients who needed interpreters and always had one available. Our results suggest that patients who need interpreters, but do not always get to use one, perceived their care to be of lower quality and are less satisfied with communication with providers and office staff. Improving doctor-patient communication is important clinically because evidence suggests that patients that experience superior communication with providers have better diabetes ${ }^{27}$ and hypertension-related outcomes ${ }^{28}$. Moreover, high-quality patient-provider communication is a cornerstone of primary care and a key ingredient in delivering high quality patient-centered care $^{29,30}$. Thus, health care organizations serving communities with growing Latino populations can significantly improve the quality of care they provide by always having interpreters available to Spanish-speaking patients who need them.

Our main finding that patients who needed interpreters and always used one had higher scores compared with patients who did not need an interpreter is consistent with that of a previous study of Spanish-speaking families enrolled in health plans participating in the California Children's Health Insurance Program (SCHIP) ${ }^{22}$. In that study, the provision of interpreters resulted in a graded relationship with reports about provider communication. By contrast, we did not find an obvious graded relationship between interpreter use (always/ usually/sometimes/never) and the global and composite measures. It is important to note that our study included adult patients in different ambulatory care settings where comparable studies have surveyed Latinos enrolled in health plans ${ }^{22,23}$. Moreover, our sample accounts for patients of a different sociodemographics including individuals without insurance coverage. Our results resemble those from a similar survey study of uninsured adult Spanish-speaking patients that received care in urban hospitals and extend that study to incorporate findings for Spanish-speaking Latinos in ambulatory care settings ${ }^{18}$.

Higher ratings of care by patients who needed and always got an interpreter than those who did not need interpreters may be explained by the belief that interpreters do more than interpret for patients; they function as a link between patients and health systems. They are plausibly unofficial health coaches or system navigators who provide linguistic services and beyond, possibly including social support for patients ${ }^{22}$.

Limitations of this study prevent any inferences about causal effects of interpreters on communication between patients and doctors/staff. Our results may not be generalized to other populations with LEP or to all Latinos with LEP in the US. The large number of females in the sample and the site selection criteria-growing Latino populations-may also affect the generalizabilty of the results. In this analysis, the type of interpreter 
used (e.g., professional, family member, or clinical staff) is not taken into account. Because data are from surveys and not directly observed clinical encounters, one cannot completely discount reporting bias from participants or verify the use of interpreters. Also, we cannot exclude instrument bias as a possible explanation for these results. ${ }^{31,32}$ Because we made slight changes to some CAHPS $\AA$ items, we do not recommend benchmarking. Finally, we focused on patient reports of care and did not have systematic clinic-level measures of interpreter service structure for each site that participated in HJ. This potentially biased our results and limited us from profiling individual sites. However, because participating sites were selected from 128 sites based in part on the need for new or expansion of existing language access services for Spanishspeaking Latinos, large differences in our results are unlikely to arise from clinic-level factors. Even if clinic-level language services explain the variation in patient ratings of care by interpreter use, our results would still suggest that having sound structural implementation of interpreter services leads to greater patient satisfaction with care ${ }^{33}$. Because some evidence suggests that clinic-level factors are linked to enhanced culturally appropriate provider behavior ${ }^{34}$ and greater patient satisfaction with care $^{33}$, associations between clinic-level variables, interpreter use, and outcomes should be investigated in future studies.

Our study has policy implications. Given the current environment of health care reform, mention should be made that as primary care retools itself with a focus on patientcentered care ${ }^{30}$, clinicians should consider incorporating interpreters into primary care teams that provide culturally and linguistically appropriate care ${ }^{35}$. When language concordance between doctors and patients is not possible ${ }^{15}$, the incorporation of professionally trained interpreter services is essential for clinics that serve limited English speaking populations. Although not consistently enforced, federal regulations require that health care organizations provide culturally and linguistically appropriate care to patients ${ }^{36,37}$. Unfortunately, the quality of interpreters may vary greatly across settings because evidence-based criteria for what constitutes a qualified interpreter is lacking. Further research is needed to determine how the quality of interpretation is associated with patient-centered health outcomes.

We conclude that patient ratings of overall health care and doctor/office staff communication vary by availability of interpreters for Spanish-speaking patients in different ambulatory care settings. Our results demonstrate that among Spanishspeaking Latinos, always having an interpreter available for those that need them is associated with higher ratings of patient communication and satisfaction with overall ambulatory care. With the continued growth of Latino populations in the US, health care systems that invest in professional interpreter services will be well positioned to provide high quality of care to linguistically diverse populations.

Acknowledgment: We would like to acknowledge Robert Bjork, $\mathrm{PhD}$, for his editorial comments and Chi-Hong Tseng, PhD, for his feedback on the manuscript's statistical analyses.

Funding: Funding support for Dr. Moreno was provided by the Robert Wood Johnson Foundation Clinical Scholars Program at UCLA. This research was supported by a grant from the Robert Wood Johnson Foundation to RAND (PI: Morales, e-mail: morales.l@ghc.org). Dr. Moreno also received partial support from the California Endowment and the UCLA Resource Center for Minority Aging Research/Center for Health Improvement of Minority Elderly (RCMAR/CHIME) under NIH/NIA Grant P3OAG021684, and the content does not necessarily represent the official views of the NIA or the NIH.

Conflict of Interest: None disclosed.

Open Access: This article is distributed under the terms of the Creative Commons Attribution Noncommercial License which permits any noncommercial use, distribution, and reproduction in any medium, provided the original author(s) and source are credited.

Corresponding Author: Gerardo Moreno, MD, MSHS; Department of Family Medicine, David Geffen School of Medicine at UCLA, Los Angeles, CA, USA (e-mail: gemoreno@mednet.ucla.edu).

\section{REFERENCES}

1. Hispanics in the United States, Population Estimates July 1, 2000 to July 1, 2006: Ethnicity and Ancestry Branch, Population Division, US Census Bureau;2006.

2. Flores G, Torres S, Holmes LJ, Salas-Lopez D, Youdelman MK, Tomany-Korman SC. Access to hospital interpreter services for limited English proficient patients in New Jersey: a statewide evaluation. J Health Care Poor Underserved. 2008;19(2):391-415.

3. Regenstein M, Mead H, Muessig KE, Huang $\mathbf{J}$. Challenges in Language Services: Identifying and Responding to Patients' Needs. J Immigr Minor Health. Jun 72008.

4. Davis JA, Whitman MV. Organizational characteristics associated with cultural and linguistic service provision within Alabama hospitals. Health Care Manag (Frederick). 2008;27(1):79-88.

5. Bradshaw M, Tomany-Korman S, Flores G. Language barriers to prescriptions for patients with limited English proficiency: a survey of pharmacies. Pediatrics. 2007;120(2):e225-235.

6. Weiss L, Gany F, Rosenfeld P, et al. Access to multilingual medication instructions at New York City pharmacies. J Urban Health. 2007;84 (6):742-754.

7. Cunningham P, Banker M, Artiga S, Tolbert J. Health Coverage and Access to Care for Hispanics in 'New Growth Communities' and 'Major Hispanic Centers'. Kaiser Commission on Medicaid and the Uninsured. September 2006.

8. Jacobs E, Chen AH, Karliner LS, Agger-Gupta N, Mutha S. The need for more research on language barriers in health care: a proposed research agenda. Milbank Q. 2006;84(1):111-133.

9. Cheng EM, Chen A, Cunningham W. Primary language and receipt of recommended health care among Hispanics in the United States. J Gen Intern Med. 2007;22(Suppl 2):283-288.

10. Lurie N, Zhan C, Sang1 J, Bierman AS, Sekscenski ES. Variation in racial and ethnic differences in consumer assessments of health care. Am J Manag Care. 2003;9(7):502-509.

11. David RA, Rhee M. The impact of language as a barrier to effective health care in an underserved urban Hispanic community. Mt Sinai J Med. 1998;65(5-6):393-397.

12. Morales LS, Cunningham WE, Brown JA, Liu H, Hays RD. Are Latinos less satisfied with communication by health care providers? J Gen Intern Med. 1999;14(7):409-417.

13. Hu DJ, Covell RM. Health care usage by Hispanic outpatients as function of primary language. West J Med. 1986;144(4):490-493.

14. Karliner LS, Jacobs EA, Chen AH, Mutha S. Do professional interpreters improve clinical care for patients with limited English proficiency? A systematic review of the literature. Health Serv Res. 2007;42(2):727-754.

15. Flores G. The impact of medical interpreter services on the quality of health care: a systematic review. Med Care Res Rev. 2005;62(3):255-299.

16. Ngo-Metzger $\mathbf{Q}$, Sorkin DH, Phillips RS, et al. Providing high-quality care for limited English proficient patients: the importance of language concordance and interpreter use. J Gen Intern Med. 2007;22(Suppl 2):324-330.

17. Baker DW, Hayes R, Fortier JP. Interpreter use and satisfaction with interpersonal aspects of care for Spanish-speaking patients. Med Care. 1998;36(10): 1461-1470.

18. Andrulis D, Goodman N, Pryor C. What a difference an interpreter can make: health care experiences of uninsured with limited English proficiency. MA: The Access Project. Boston; 2002. 
19. Wu S, Ridgely MS, Escarce JJ, Morales LS. Language access services for Latinos with limited English proficiency: lessons learned from Hablamos Juntos. J Gen Intern Med. 2007;22(Suppl 2):350-355.

20. Morales LS, Ridgely MS, Escarce JJ, et al. Language access Service for Latinos with limited English proficiency: The National Evaluation of Hablamos Juntos. NJ March: Final Report. Princeton; 2007.

21. Hargraves JL, Hays RD, Cleary PD. Psychometric properties of the Consumer Assessment of Health Plans Study (CAHPS) 2.0 adult core survey. Health Serv Res. 2003;38(6 Pt 1):1509-1527.

22. Morales LS, Elliott M, Weech-Maldonado R, Hays RD. The impact of interpreters on parents' experiences with ambulatory care for their children. Med Care Res Rev. 2006;63(1):110-128.

23. Mosen DM, Carlson MJ, Morales LS, Hanes PP. Satisfaction with provider communication among Spanish-speaking Medicaid enrollees. Ambul Pediatr. 2004;4(6):500-504

24. Royston P. Multiple Imputation of missing values: update. The Stata Journal. 2005;5(2):1-14

25. Moreno G, Tarn DM, Morales LS. Impact of interpreters on receipt of new prescription medication information among Spanish-speaking Latinos. Med Care. 2009;47(12):1201-1208.

26. Slonim AD, Marcin JP, Turenne W, Hall M, Joseph JG. Pediatric patient safety events during hospitalization: approaches to accounting for institution-level effects. Health Serv Res. Dec 2007;42(6 Pt 1):22752293; discussion 2294-2323.

27. Schillinger D, Piette J, Grumbach K, et al. Closing the loop: physician communication with diabetic patients who have low health literacy. Arch Intern Med. 2003;163(1):83-90.
28. Perez-Stable EJ, Napoles-Springer A, Miramontes JM. The effects of ethnicity and language on medical outcomes of patients with hypertension or diabetes. Med Care. 1997;35(12):1212-1219.

29. Stewart M, Brown JB, Donner A, et al. The impact of patient-centered care on outcomes. J Fam Pract. 2000;49(9):796-804.

30. Reid RJ, Fishman P, Yu O, et al. A patient-centred medical home demonstration: a prospective, quasi-experimental, before and after evaluation. Am J Manag Care. 2009;15(9):e79-87.

31. Morales LS, Reise SP, Hays RD. Evaluating the equivalence of health care ratings by whites and Hispanics. Med Care. 2000;38(5):517-527.

32. Morales LS, Weech-Maldonado R, Elliott M, Weidmer B, Hays RD. Psychometric properties of Spanish Consumer Assessments of Health Plans Survey. Hispanic Journal of Behavioral Sciences. 2003;25(3):386409

33. O'Brien M, Shea J. Disparities in patient satisfaction among Hispanics: the role of language preference. J Immigr Minor Health. Jul 212009.

34. Paez KA, Allen JK, Carson KA, Cooper LA. Provider and clinic cultural competence in a primary care setting. Soc Sci Med. 2008;66(5):12041216.

35. Bodenheimer TS, Grumbach K. Improving Primary Care: Strategies and Tools for a Better Practice. New York, NY: McGraw-Hill; 2007.

36. National Standards for Culturally and Linguistically Appropiate Services in Health Care: Executive Summary. Washington, DC: US Department of Health and Human Services Office of Minority Health; March 2001.

37. Youdelman MK. The medical tongue: US laws and policies on language access. Health Aff (Millwood). 2008;27(2):424-433. 